\title{
Geopolitics of Energy Pipelines: Case Study of TAPI and IP gas Pipelines
}

\author{
Adil Rana Rajpoot ${ }^{1}$, Sharyl Naeem ${ }^{2}$ \\ ${ }^{1}$ M.Phil. in International Relations from NDU, Islamabad. \\ ${ }^{2}$ M.Phil. in Political Science from GCWUS. \\ Email:adil.rajpoot@hotmail.com ${ }^{l}$ \\ Email:_sassi.sharyl@gmail.com ${ }^{2}$
}

\begin{abstract}
This research is about the acute energy crisis being faced by Pakistan since decades. Energy crisis has exploited Pakistan economically, socially, domestically and internationally. As, gas is the cheapest source of energy production so IP and TAPI gas pipelines projects are of greatest significance for Pakistan and for South Asian and Central Asian regions, as well. Qualitative research method is used to conduct this research. This study will explain the history and current situation of IP and TAPI gas pipelines projects, along its feasibility aspects. This research will analyze that how IP and TAPI gas pipeline projects is valuable for Pakistan's economy and to overcome energy crisis within Pakistan and within the region. Moreover, TAPI and IP gas pipeline project will prove to be a game changer as it has vast geo-strategic implication for the Central Asian states. TAPI gas pipeline project will become a source of energy transfer and will able to maintain cordial relations within Pakistan and India. These pipelines will become a major source of regional integration, economic interdependence and mutual cooperation.
\end{abstract}

Keywords: Geo-Strategic, TAPI, IP, gas pipelines, energy crisis.

\section{INTRODUCTION}

"Few modern ideologies are as whimsically all-encompassing, as romantically obscure, as intellectually sloppy, and as likely to start a third world war as the theory of "geopolitics."(Clover Charles.1999, p.9)

The need for more robust energy resources has increased in the 21 st century with the growing economies of the world are pursuing the more advanced 'technological reach' to the natural resources of the world. The more the technological development is taking a new reformed shape, the more the states are looking for new resources of energy. In the coming years, natural gas could be considered as the most important source of energy by the states to fulfill their increased energy requirements.

From strategic point, the politics of energy resources is becoming an influential and game changer element for regional as well as international powers. The developed and technologically advanced states of the North and the developing or third world states of the South, all are entering into a new phase of worldly affairs where the need for energy resources have become a prominent agenda of the state as well as international politics. This thing has generated a political conundrum of 'geo-politics' between the states for the pursuit of their political, economic and military, technological and energy requirements.

The term geopolitics was first coined and provided a rational space by Rudolf Kjellen in 1899 . But the term has historical roots in the late nineteenth century. The rivalries between the empires of the mid and late nineteenth century introduced this concept in various institutions and academia of the late nineteenth century (Guzzini, S.2003). Geopolitics has always remained a traditional approach under intellectual umbrella of state politics and identity clashes over the centuries. (Gökmen, S. R. 2010). Defining the term 'geopolitics', in its conscience context, requires a deep insight into the historical developments.

For instance, the Encyclopedia Britannica defines the term geopolitics as "analysis of the geographic influences on power relationships in international relations." Another definition is given in the 
Longman Dictionary of Contemporary English which says, "The study of the effect of a country's position, population, etc. on its politics."Kolesnikova, O., \& Gelbukh, A.(2010, November). The definition of geopolitics provided by Rudolf Kjellen is "the theory of the state as a geographical organism or phenomenon in space.”(Cahnman, W. J. 2017). Karl Haushofer, a renowned geopolitical theorist, has given a more precise and scientific definition of the term geopolitics.

According to Haushofer, "geopolitics is a new science of the state, a doctrine on the spatial determinism of all political processes, based on the broad foundations of geography, especially of political geography.”(Williams, A. J., Jeffrey, A., McConnell, F., Megoran, N., Askins, K.,Gill, N. ... \& Pande, R. 2013). Keeping in view all these definitions the main idea that comes to mind is the 'game theory' that is applicable to every situation whether it is the international political order reframing itself for the promotion of more peace and stability or on the contrary it may be the 'great games' which have been and recently been played by the major powers in different regions of the world, to get control over natural resources of those regions.

Keeping aside every international agenda which has remained dominant for years to enhance the interdependence among states, the main political and economic aim of every state has been to become resource sufficient in order to fulfill the energy requirements for their developmental process. Geopolitics of energy is not a new phenomenon and it captured the minds of various renowned leaders of different major powers to replicate the idea of acquiring more resources for their economic and commercial needs and to enhance their military capabilities based on technological developments which are taking place rapidly throughout the whole world.

There has always been a very close link between the energy and geopolitics. The historical developments in the 20th century has shown that energy remained the main core element during the whole century on which the winners of wars were decided and major oil producers bandwagon themselves to deter the superpowers to alter the international order. In the 21 st century, the demand for more energy in a capsulized form for the development of various technical and infrastructure projects has forcefully proclaimed that states should adopt new and more favorable energy policies in order to overcome the blooming needs for energy resources.

For this purpose, major powers and other emerging economies of the world are trying to discover new and more reliable energy resources. In the contemporary era, the Central Asian region is considered more resourceful region as compared to other resource rich regions of the world. Like other states searching for new energy reservoirs, Pakistan and India are also focusing on their energy needs. The resource and energy abundant Central Asia is becoming a hub for the accomplishment of future energy needs of different states.

Turkmenistan possess excessive amounts of natural gas that predictably been utilized for the coming four or five decades. Turkmenistan's standing is at number 4 in the world in respect to the possession of the largest natural gas reserves with the ratio of $4.3 \%$.(bp. 2012). Turkmenistan presents a neutral foreign policy posture in which the energy policy is the uppermost priority of the state. Turkmenistan is dealing with various energy partners to which its foreign policy has always remained balanced and based on the doctrine of neutrality. (Berdikeeva, S.2007). Based on this principle, the attractiveness for other states has increased in the energy market of the resource rich country. The same is the case with Pakistan, India and Afghanistan. These three states are in a search of energy rich country to fulfill their increasing demands for robust energy resources.

The TAPI gas pipeline provides an opportunity for these states to boost bilateral relations and the economic cooperation with the benefit of acquiring new energy zones for the fulfillment of their increasing energy needs. This paper seeks to provide an analytical framework to understand the pros and cons of the TAPI gas pipeline by comparing it with the IP gas pipeline project. The theme of the paper would be a case study in which the TAPI and IP gas pipelines would be discussed.

The paper would revolve around some core questions that are, how would the new great game in central Asia affect the politics of energy pipelines? How can the instability in Afghanistan affect the TAPI project? What would be the regional implications of TAPI gas pipeline project? How can Pakistan and India bridge their bilateral gaps through TAPI? How would the United States and Russia pursue the Turkmenistan's new policies towards energy pipelines? What policy imperatives could Iran come up with 
in relation to IP gas pipeline project? The main argument that can be generated is the energy politics of TAPI and IP gas pipelines is marked by new great game and instability of Afghanistan.

The main theoretical paradigm in which the case study of TAPI and IP gas pipelines can be discussed is the Heartland theory. Halford Mackinder a renowned British geographer presented a theory in 1904 in which he described the Central Asia as a heartland of natural resources. In his famous thesis titled "The Geographical Pivot of History", he stated that the whole Central Asian region possess a vast range of natural resources that if a state gets the control over these resources, that state can become the world empire. (Mackinder, H. J.1962)

The theory takes into account the role of geography in the international politics and relates it to the geopolitical environment both literally and figuratively. From literally point of view, the theory explains the concept of pivot area or heartland, which is a resourceful region in Eurasia and has a big size in respect to territory expanded over the whole central Asian region. Any country that gets the control of this sizeable region rich in natural resources, can thus be able to determine its supremacy over the world politics.

Figuratively, the main concept of the theory revolves around the geographical resources as a function which has a part to play in international politics. This figurative view becomes narrow and deterministic in nature to only discuss the international politics in a functional way related to geography only. Mackinder has highlighted in his theory that any state getting command over the East Europe will be able to command Heartland and this will lead to the hold of that state over the World-Island, and once the command of the World-island is in the hands, then the whole world will be ruled by that state. (Mackinder, H. J.1962). The heartland theory creates a critical geostrategic link between the control over the land and the use of political power thus converting it into geopolitical power. While presenting his theory to the Royal Geographical Society in 1904, Mackinder explained this connection by stating that:

"The political power, when it is balanced, is the product of, on one hand, the geographical conditions, including and culminating the economic and strategic ones, and, on the other hand, the relative numerical counts of men, the strengths, equipment and the proper organization and balancing of the people who are competing"(Mackinder, H. J.1904)

In the light of this theory, the New Great game in Central Asia can be explained on the basis of political and military involvements of the major powers like the US, Russia and some of the EU countries. The US involvement in the region is evident from the fact that the US has always tried to maintain its influence in the Caspian region only to get access to the natural resources. One of the declassified documents of the Pentagon revealed the basic policies of the US administration and military establishment in the central Asian region by stating:

"The core objective of the foreign missions is to prevent and counter the reemergence of a challenging power that can prove to be fatal for the American presence in the region. This is the priority and the highest dominant consideration that involves strategies and schemes for the prevention of the control over the resources of this region by any hostile power, which could lead to its global hegemony. The American strategy should be focused on devising such policies through which the emergence of any future global competitor must be suppressed."(Olcott, M. B. 1998) 


\section{Turkmenistan-Afghanistan-Pakistan-India (TAPI) Gas Pipeline}

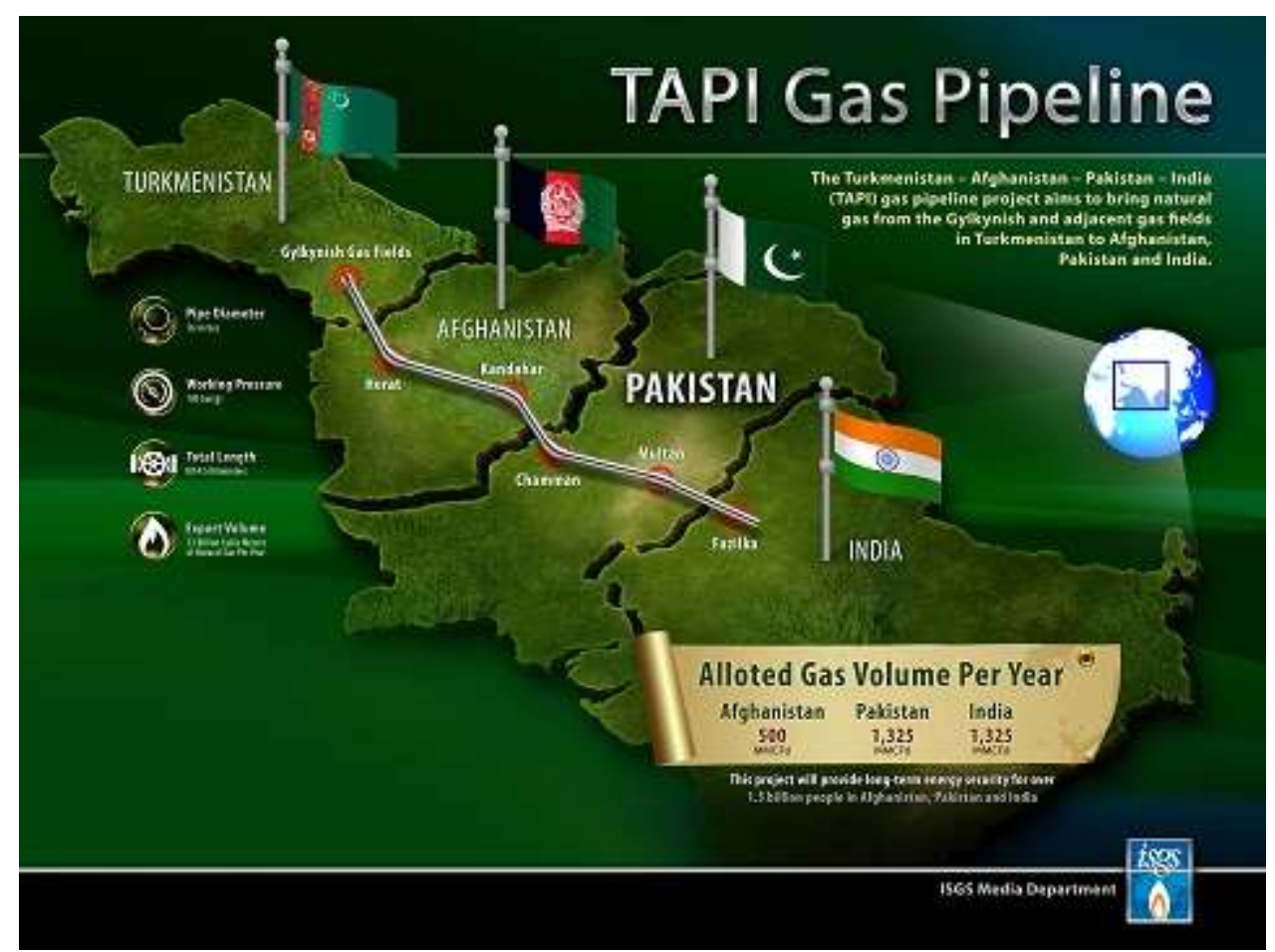

TAPI which was known as the Trans-Afghanistan Gas pipeline in the 1990s was planned in 1995 for energy supply to Afghanistan and Pakistan. The project is still facing hurdles and yet to be completed in its full practical form. With the consensus of the states, TAPI was initiated to carry gas from the gas rich Galkynysh field of Turkmenistan to Pakistan and India through Afghanistan. This project is funded by Asian Development Bank and it aims to transport tons of natural gas to Pakistan, Afghanistan and India. The whole project would cost US \$ 10 billion. The pipeline will cover a distance of more than 1600 $\mathrm{km}$ (Plocki, M.2013) and if completed, this pipeline will become the first ever Central Asian energy transportation pipeline to South Asian markets.

The prescribed TAPI gas pipeline under specific plans will have entry points in Afghanistan at Herat and then it will run through Farah, Helmand and Kandahar and entering into the territory of Pakistan by making its way through parts of Baluchistan and Multan and finally reaching its end point in India at Fazilika. The expected total length of TAPI gas pipeline will be divided in such a way that 144 $\mathrm{km}$ will be passing through Turkmenistan, Afghanistan will have more than $700 \mathrm{~km}$, Pakistan will be having approximately $800 \mathrm{~km}$ share. The gas which would be pumped through the pipeline is of 90 MMcmd of which India and Pakistan will get $38 \mathrm{MMcmd}$ each and the share of Afghanistan would be 40 MMcmd. (Maini, T. S., \& Vaid, M.2013). The president of Afghanistan, Ashraf Ghani at the Ground Breaking Ceremony of TAPI pipeline, in December 2015 expressed his view in the following manner (Ishaque, W, Qumber, G, \& Shah, S. J. 2017)

"TAPI is the beginning of a cluster approach to infrastructure. First, comes the gas pipeline but the discussions that we have had among four of us have resulted in agreement that TAPI will be accompanied by a fiber optic network as well. This will be the quickest way and the most reliable way from India to Pakistan to Afghanistan to Turkmenistan all the way to Europe and that is significant. In addition, later we will witness another historic first which is transmission of electricity from Turkmenistan through Afghanistan to Pakistan which will run parallel to TAPI. We in Afghanistan are committed to make the railways, highways and our canals and water management all brought together so what we see is not TAPI but a super highway of cooperation and coordination that will connect again South Asia and Central Asia together.’(Duta, A. E. (2017). 


\section{Energy Needs of Afghanistan and Pakistan}

In the contemporary era, the sustainable sources of energy are very important and access to these resources can make every individual's life full of opportunities. The sustainable supply of energy is a key element for the development and economic growth of a country. Different facts and figures revealed that human development can reach the highest mark if cost effective access to energy is made easy. In case of Pakistan, the domestic energy scenario requires a deep insight to understand the existing and increasing energy needs of the country. Pakistan's main reliance for its energy fulfillment is on the domestic as well as imported petroleum products.

The share of gas in the energy sector is the highest presently and its demand is at height for future references. The usage of gas in energy sector constitutes about 48.2 per cent of the whole energy supply. (Munir, M.,Ahsan, M., \& Zulfqar, S.2013). The gas infrastructure, transmission and distribution networks in Pakistan are one of the most developed networks of South Asia. It comprises 11,538 km transmission, 114,982 km distribution and 31,058 services gas pipelines in order to provide more than 7.9 million consumers with daily supply of more than 4 billion cubic feet of gas on the daily basis. Govt, $\mathrm{O}$. P. 2015).

Pakistan is facing energy shortages due to which its development could be effected. Various energy experts working on different renewable energy projects claim that the country is moving faster towards an energy crisis. One of the renowned energy experts in Pakistan says that the energy requirement is the basic thing as per the developmental projects and sustainability of economic growth and development totally depends on energy. The process of industrial and technological development has increased the demand of the energy supply, hence have created energy deficit presently. (Anwar, J. 2010)

According to the World Bank report of 2014 highlights that currently, Pakistan is facing many challenges in the energy sector, which can affect the ongoing development process. The energy shortages are expanding and inefficiencies have delayed the investments into the energy sector. The power generation capacity in Pakistan is still stagnated since 2006 and working capacity is not crossing the limits of 94-98 TWh. The more investment into the energy sector can improve the situation in the country. (Amber, K. P., \& Ashraf, N. 2014)

Afghanistan has experienced an immense availability of energy during the past decade, especially the urban areas of Afghanistan have been provided new energy sources, but still the country has very low ratio of electricity consumption per capita. The country has a very weak industrial base and what it had in the 1960s was destroyed during the Soviet invasion. Afghanistan is a landlocked country and is totally dependent on the moods of its neighbors for conducting any type of trade. The energy shortage and the aim to build an industry require a proper setup in which the flow of energy is very important. In the Afghanistan National Development Strategy (ANDS) it has been mentioned that only 6 per cent of the population is benefitting from the available energy resources. Moreover, the development strategy has also identified energy as the supreme needed commodity for industrial and social development of the country. The development of the energy sector is the priority which has been discussed in the ANDS and more foreign investment is the key goal to improve the development and sustainability of the energy sector.(Sherman, J. 2009).

\section{Geo-Strategic importance of TAPI}

The strategic significance of the project is tremendous. Once completed, TAPI can become a game changer and provide greater impetus to regional economic integration projects which have thus far been a non-starter. The agreement is between the states and the change of regime in any partner country will have no impact on the project. It would be one of main instruments for enhancing regional stability and improving living standards in South and Central Asia. TAPI will provide cheap gas for Pakistan, India, transit fee for Afghanistan and Pakistan, and energy market to Turkmenistan, which will add to the economic dividend of all the countries. It will provide cheaper and cleaner energy to consumers which would bring economic prosperity and also reduce high ratios of inflation. It will generate incomes/revenues that can be used for developing the social sectors especially education, health, clean water and housing.

It is estimated that the TAPI project will reduce poverty by expanding the use of natural gas resources and enhancing sub regional economic cooperation. It will lead to employment generation and 
thus may deprive the conditions by which young people join extremist groups. It would also lead countries to devise joint strategies to address security concerns that would impinge on their economic interests. TAPI thus has the potential of being a CBM in South Asia. If equitable distributions of benefits are percolated to the common people it would help build local ownership. It could help improve security governance and service delivery as the governments will need the support of the local populace, particularly in the volatile areas and the people would in turn; protect such projects of which they would be beneficiaries.

It would have a 'force multiplier' effect in initiating other such projects and enhancing bilateral and regional connectivity. Building trust between people and the governments, the pipeline would be able to compel countries in the region to move away from zero sum competition towards mutually beneficial frame work of cooperation. In a classic security-development (similar to chicken \& egg) dilemma, the development rationale will help build constituencies of peace and deny the conditions for the extremist groups to thrive.(Weitz, R. (2015)."

\section{Two Proposed Pipelines in South Asia}

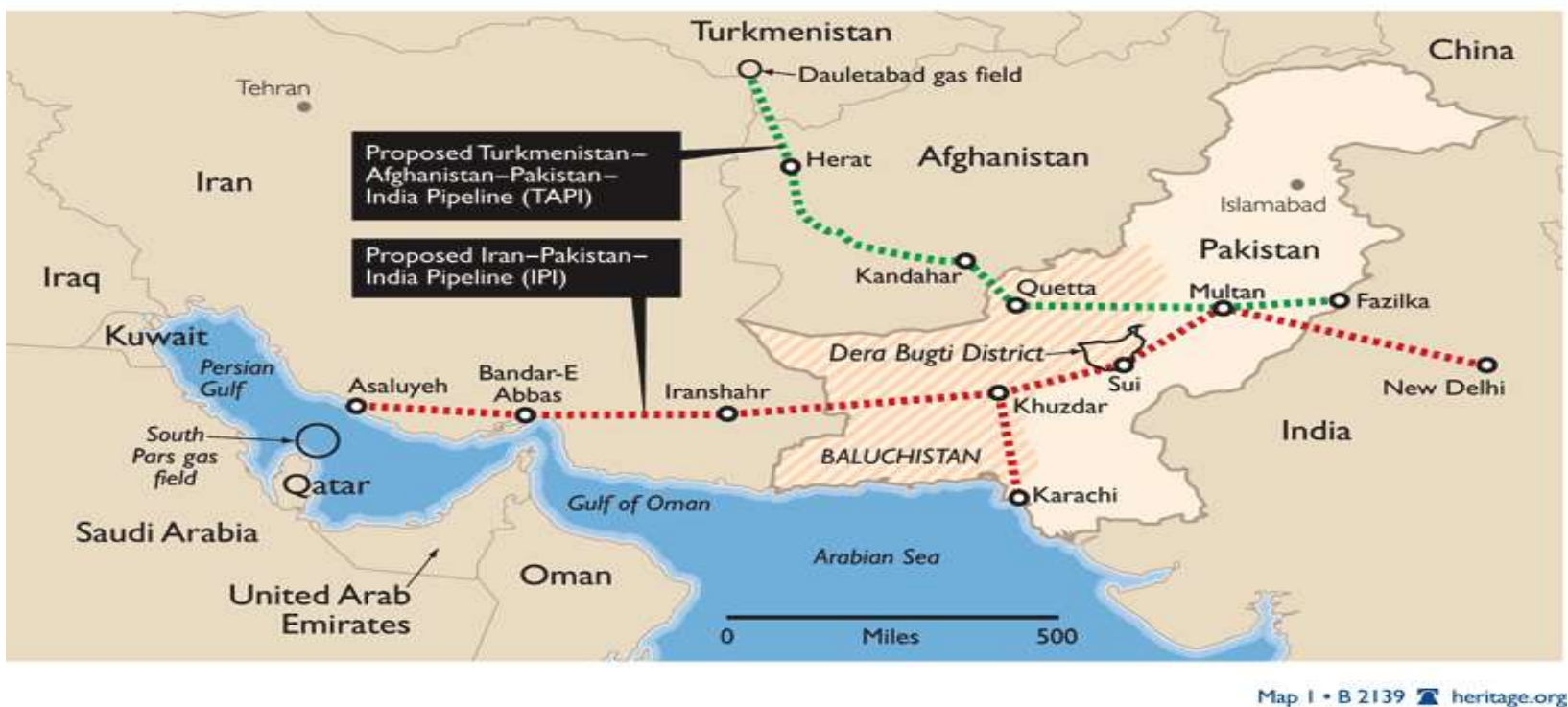

Source: Heritage Foundation (Geocurrent.info).

\section{Iran-Pakistan Gas Pipeline}

Being neighbors under the umbrella of Islamic brotherhood, Iran and Pakistan have a long history of diplomatic relations, a mix of cordial and equivocal. In 1990s Iran and Pakistan agreed to build a gas pipeline for the transmission of natural gas to Pakistan as a new energy resource. Iran Pakistan Gas Pipeline project remained under discussion for several years from 1994 onwards till 2000s. In the beginning, the project deal was signed between Iran and Pakistan only in 1994, but later in 1999 Iran also included India as a partner to the energy project. In 2009 India withdrew from the IP gas pipeline project after having scored a nuclear deal with the US in 2008. Iran has already completed the construction of the pipeline at its half and Pakistan hasn't yet started the construction work at its side. Various analysts are of the opinion that IP gas pipeline would offer cheaper rates and it would be cost effective. The pipeline would certainly have some geo-economic and geo-political implications. The total cost of the whole project is estimated at $\$ 3$ billion and the savings of oil imports for Pakistan would increase by $\$ 5.3$ billion.

\section{Politics Involved}

Banged by the foreign interventions and internal political chaos, the IP gas project still remains a highly resenting issue to be resolved soon. The progress on the project has been hindered by various hidden and open complicated issues. The most highly resonant issue, which has always risked the existence of this pipeline project, is the US sanctions on Iran. The other sanctions which were imposed on Iran by the United Nations and European Union were directly against the nuclear ambitions of the state, 
but the American sanctions are somewhat different in nature. Iran was put on a list of those countries who were involved in the promotion and execution of terrorism, in order to impose more economic and political sanctions on the Islamic state. (Petalas, C. 2016). The sanctions on Iran has a history which dates back to 1979 when after the Tehran Hostage Crisis, President Jimmy Carter took severe and intense initiatives against Iran by freezing Iranian assets and imposing economic sanctions. (Petalas, C. 2016). The Deal with Iran is the Best-case Scenario the International Community Could Achieve in the Current Geopolitical Environment. AIR WAR COLLEGE MAXWELL AFB United States. In 1990s President Clinton took more harsh measures against Iran and George Bush continued the tradition. Barack Obama reshuffled the sanctions and for this purpose Iran Sanctions Act (ISA) was proposed. Iran's energy sector was kept under surveillance by enforcing ISA so that any investment and any developments in the energy sector including the pipelines can be monitored. (Kerr, P. K., \& Katzman, K.2018)

After the signing of a nuclear treaty between the Iran and P5+1 back in November 2013, Iran was relieved in some sanctions but the energy sector remained under the same US sanctions. (Shaoxian, L.2015). Another factor that created an enormous issue with the IP gas project was the price mechanism. Apart from this, the geopolitical environment of the Middle East could also have immense effects on the future of the IP gas pipeline project.

\section{Comparative Analysis}

The 21 st century is the century of 'resource acquisition', as many states are pursuing energy politics with a more persuasive ways of getting themselves involved in the 'great game' of energy resources. Comparatively analyzing the costs and benefits of the TAPI and IP gas pipelines, the states which are involved may be thinking to opt for alternative sources of energy. There are definite risks of more instability in the Southern region of Afghanistan and the absence of good governance and lack of political will in the leadership, the region is showing unreliable security environment which is not amicable for any energy pipeline (its construction and transportation). Another perspective is the political aim of the US and its strong presence in the Central Asian region.

The US, might possibly, would back the TAPI pipeline project for reducing the dependency of its ally states on the Russian gas resources. In the case of Pakistan and India, both the states are at a 'winwin' level retrospect to TAPI. But in the case of IP gas pipeline, India would be at loser's end because of its reluctance to build an Iranian pipeline which would pass through the Pakistani territory into the Indian. The main factor behind the failure of the IP gas pipeline is the pressure exerted by the US on Iran and Indo-US strategic partnership. In case, if the security situation in Afghanistan remains the same for the coming few years, then Pakistan can opt for IP gas project by gaining support from the Chinese and Russian sides.

\section{CONCLUSION}

TAPI gas pipeline project could become a game changer in the region because of some fundamental factors involved in the background of the development of this project. It would have huge geo-strategic implications for those states that are currently benefitting from the gas and oil reserves of Central Asian region. The biggest alarming situation would be for the US as it is the main player in central Asian geopolitics of energy resources. The great game which is still going on in the region comprises six main players; the US, Russia, China, Iran, Turkmenistan, India and Pakistan. For regional integration and better bilateral ties, the cross border energy projects play a significant role. In the case of both TAPI and IP gas pipelines, the states which are involved can benefit from the fruits of this energy project.

The economic crisis and mismanagement of its natural resources with continuous aspirations for the pursuit of nuclear capability, Iran still remains not a viable option for energy trade. The US withdrawal from the Iran Nuclear deal and emerging sentiments of more UN sanctions, have made Iran an erratic business partner. Moreover, the US-India strategic partnership is a key in determining the major aspects of the energy deals in the region. Both the US and India have linked interests in Persian Gulf, economic and strategic. In the Central Asian region, the US doesn't want to lose its influence. In short, TAPI gas pipeline, if completed successfully, can become a source of energy transfer and for better cordial relations between the two rival states (Pakistan and India) and for regional integration on the basis of mutual cooperation and economic interdependence. 


\section{RECOMMENDATIONS}

* It's in the economic and geopolitical interest of Pakistan to pursue IP gas pipeline because it's most feasible and cheapest option for Pakistan to counter its economic and energy crisis.

* Proactive Political leadership and good governance is needed for the completion of these pipeline projects because they are in the national interest of Pakistan. As, Pakistan is one the big gas market in region so it should utilize these energy opportunities.

* Pakistan can become an energy corridor within the region if it will expand IP and TAPI to other regional states. By extending TAPI and IP to Bangladesh and China, Pakistan will get free trade route to China and Bangladesh and help to boost its economy. In short, these energy pipelines will provide free trade within the region which is not only beneficial to Pakistan but all regional states.

* Moreover, TAPI and IP gas pipelines will help to promote peace, stability, cooperation and economic stability within the South Asia and Central Asia region.

\section{REFERENCES}

[1] Clover, C. (1999). Dreams of the Eurasian Heartland-The Reemergence of Geopolitics. Foreign Aff., $78,9$.

[2] Guzzini, S. (2003). 'Self-fulfilling geopolitics'? or: the social production of foreign policy expertise in Europe. Danish Institute for International Studies, Copenhagen.

[3] Gökmen, S. R. (2010). Geopolitics and the study of International Relations. Middle East Technical University.-2010.-226 p.

[4] Kolesnikova, O., \& Gelbukh, A. (2010, November). Supervised machine learning for predicting the meaning of verb-noun combinations in Spanish. In Mexican International Conference on Artificial Intelligence (pp. 196-207). Springer, Berlin, Heidelberg.

[5] Cahnman, W. J. (2017). Concepts of geopolitics. In Social Issues, Geopolitics, and Judaica (pp. 155-161). Routledge.

[6] Williams, A. J., Jeffrey, A., McConnell, F., Megoran, N., Askins, K., Gill, N., ... \& Pande, R. (2013).

[7] Interventions in teaching political geography: Reflections on practice. Political Geography, 34, 24-34.

[8] bp. (2012). bp Statistical Review of World Energy June 2012. British Petroleum June.

[9] Berdikeeva, S.(2007). Turkmenistan's energy policy: risks and opportunities. Insight Turkey, 9(3), 123-135.

[10] Mackinder, H. J. (1962). The Geographical Pivot of History” in Democratic Ideals and Reality.

[11] Mackinder, H. J. (1904) The geographical pivot of history. Royal Geographical Society.

[12] Olcott, M. B. (1998). The Caspian's false promise. Foreign Policy, 95-113.

[13] Plocki, M.(2013) Thinking about Energy Differently in ADB Projects.

[14] Maini, T. S., \& Vaid, M. (2013). Roadblocks remain to TAPI pipeline construction. Oil and Gas Journal, $111,15-22$.

[15] Ishaque, W., Qumber, G., \& Shah, S. J. (2017). Prospects of Enduring Peace in Afghanistan: Avoiding Zero Sum Game in Af-Pak Region. Global Social Sciences Review, 2(2), 146-161.

[16] Duta, A. E. (2017). THE NUCLEAR DETERRENCE IN SOUTH ASIA. In International Scientific Conference" Strategies XXI" (Vol. 1, p. 56). " Carol I" National Defence University.

[17] Munir, M., Ahsan, M., \& Zulfqar, S. (2013). Iran-Pakistan gas pipeline: Cost-benefit analysis. Journal of Political Studies, 20(2), 161.

[18] Govt, O. P. (2015). Economic Survey 2015-16.

[19] Anwar, J. (2010). An analysis of energy security using the partial equilibrium model: the case of Pakistan.

[20] The Pakistan Development Review, 925-940.

[21] Amber, K. P., \& Ashraf, N. (2014, November). Energy outlook in Pakistan. In 2014 International Conference on Energy Systems and Policies (ICESP) (pp. 1-5). IEEE.

[22] Sherman, J. (2009). The Afghan National Development Strategy: the right plan at the wrong time. Journal of Security Sector Management, 7(1), 1-9.

[23] Weitz, R. (2015). US New Silk Road Initiative Needs Urgent Renewal. The Central Asia-Caucasus Analyst, 24.

[24] Petalas, C. (2016). The Deal with Iran is the Best-case Scenario the International Community Could Achieve in the Current Geopolitical Environment. AIR WAR COLLEGE MAXWELL AFB United States

[25] Kerr, P. K., \& Katzman, K.(2018, July). Iran Nuclear Agreement and US Exit. Congressional Research Service,[Library of Congress].

[26] Shaoxian, L. (2015). Assessing the Impact of the Iran Comprehensive Nuclear Agreement. West Asia and Africa, (5), 3. 